\title{
A vida de Cristo no Espírito Santo
}

\author{
Eduardo Leone
}

Todo montador, seja ele qual for, sonha com o longa-metragem e, de preferência, ficção. Não sei qual é a luta de foice no mercado cinematográfico, já que a minha estréia no longa aconteceu de forma inusitada.

Quando não tinha nada a fazer, a não ser viver das glórias do prêmio conquistado pelo filme $A$ morte da strip-teaser, punha-me a escriturar roteiros. E foi numa dessas desocupações que produzi um roteiro intitulado $O$ homem sem face, baseado em alguns fatos da carreira de James Dean, porém com uma leitura bastante livre, partindo de três personagens que, ao se juntarem, resolvem representar a história desse idolo; à medida que a trama evoluí, de atores eles se transformavam nas personagens do texto que representavam.

$\mathrm{Na}$ época, como julgava meu roteiro espetacular, fui pedir ao Francisco Luiz de Almeida Salles que o lesse. E, chegando ao barzinho da Galeria Metrópole, freqüentado pelo Salles, fui logo apresentado ao Luiz Carlos Barreto, que se interessou por um jovem pretendendo ser diretor de cinema, e pediu-me para levar o roteiro, com o intuito de examiná-lo melhor no Rio de Janeiro. Na minha cabeça de muitos anos a menos do que os que tenho agora, ninguém jamais recusaria aquela "obra-prima".

Mas, abrindo um parêntese nesta narrativa, posso afirmar que não estava errado, num certo sentido e claro, quando me propunha a fazer um filme sobre James Dean que ciclicamente volta à moda ditando inclusive comportamentos.

Os dias passaram, os meses passaram, e a minha paciência já estava se esgotando. Afinal de contas, o Luiz Carlos ia ou não ia topar a produção daquele filme?

Sem titubear mandei-me para o Rio de Janeiro com rumo certo: A Difilm, no Flamengo. Lá chegando fui atendido por uma senhora que se apresentou como Eliana. $\mathrm{O}$ papo ia, ela perguntou-me o que estava fazendo e eu disse que esperava pelo Luiz Carlos Barreto, a respeito de um roteiro meu. Nisso o Luiz Carlos chega e entra correndo no escritório. Af pensei: "Agora tudo vai dar certo".

Passados alguns minutos, dona Eliana voltou com o meu roteiro e me informou que o sr. Luiz Carlos não havia se interessado pelo trabalho. Essa foi a maior ducha fria que levei na vida. "Que droga", pensei; a gente faz uma escola, tenta colocar em prática os conhecimentos e fecham as portas na nossa cara e pronto? Meu sangue italiano subiu, e o filme que eu tinha previsto para James Dean iria virar um filme de Monicelli.

Mas dona Eliana havia percebido a minha raiva e começou a me contar que seu marido William estava indo para o Espírito Santo produzir um filme chamado $A$ vida de Cristo. E ela contava isso às gargalhadas e me perguntando se eu não achava uma loucura. Disse que numa pequena localidade chamada São Roque, perto de Colatina, vivia um senhor muito católico, ex-seminarista, que pretendia fazer um filme de Cristo aproveitando um teatro por ele dirigido (com o elenco local), e que era apresentado na Semana Santa. Frustrado com a recepção do Luiz Carlos, até achei engraçado fazer um filme sobre a vida de Cristo (no Brasil).
EDUARDO LEONE é professor de Montagem Cinematográfica na ECA-USP e fez a montagem de, entre outros, $A$ vida de Cristo, Os amantes da chuva e $O$ pals de Săo Sanuê, ambos de Roberto Santos.

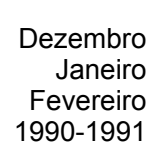

Dezembro 
Segundo a dona Eliana, estava tudo pronto, principalmente o guarda-roupa de época, que seria o mesmo das encenações do Regatieri, o ex-seminarista que dirigiria o filme com a supervisão do William Cobbett. Mas faltavam alguns pequenos detalhes, como uma lente zoom, uma segunda câmera, equipamento de montagem e daf por diante. Logo me ofereci para ajudá-la a obter esse material na escola, contanto que a montagem do filme fosse minha.

- É claro, é claro que a montagem será sua, disse-me ela sem pestanejar.

Marcamos um encontro em São Paulo e fomos falar com o Rudá de Andrade, na Época o chefe do curso de cinema. Ele não fez nenhuma objeção, a não ser o seguro do equipamento, pedindo tambem que alunos acompanhassem os trabalhos que seriam realizados no Espírito Santo. E foi assim que celebrei o meu primeiro contrato de montagem num filme de longa-metragem, ainda com a vantagem de poder assistir às filmagens.

\section{A FILMAGEM}

Para se chegar a São Roque, o caminho era complicado. De Vitória pegava-se um trem ate Colatina, e de Colatina, uma jardineira que passava quando desse na telha do motorista.

São Roque é uma localidade dominada pela famflia Regatieri. As três melhores casas da localidade pertencem a eles, telefones são três, e apenas um é público. A pensão é do Regatieri, além da principal atividade económica, o processamento de madeira, que tamberm pertence à famflia.

Não sei até hoje se foi melhor o tempo em São Roque ou a montagem do filme propriamente dita.

Logo que cheguei vim a conhecer as duas figuras principais da produção: o sr. William Cobbett, que imaginei alto, loiro e de olhos azuis, o sr. Regatieri, que imaginei um desses imigrantes mafiosos baixinhos, e que no fundo estava querendo engrupir aquele povo todo com o filme sobre a vida de Cristo. Mas a minha expectativa se inverteu: William era um nordestino de $1,60 \mathrm{~m}$ no máximo, com cara de politiqueiro, enquanto que Regatieri era loiro, olhos azuis e com um tipo elegante do norte da Itália. Content́́ssimo com a minha chegada, Regatieri me abraçou e deixou nesse abraço uma sinceridade que jamais irei esquecer.

Naquele mesmo dia, na frente da igreja, foi realizado o espetáculo que Regatieri levava há anos durante a Semana Santa.

Tudo era primitivo demais, mas possuía um certo charme. A encenação era algo que poderia ser descrito como um auto medieval, onde os acontecimentos iam se sucedendo dentro de uma ordem mais religiosa do que cronológica. Não havia uma evolução temporal marcada por algum efeito de pontuação; eram quadros que se substitufam sem que o espectador percebesse a transição, a nẫo ser pela motivação do Evangelho, algumas vezes recitado pelo proprio Regatieri.

Naquele primeiro momento de encantamento, não reparei na cenografia e nem tampouco em como seria construído o filme. Comovia-me a fé religiosa daquele homem que verdadeiramente acreditava no que estava fazendo. Mas, contraditoriamente, esse homem, tão próximo ao Evangelho, comandava com mãos de ferro o seu negócio em São Roque.

No segundo dia, e acho que isso foi até uma questão de bom senso, tentei procurar o diretor, o sr. William Cobbett. E nada de Cobbett e da equipe. Estava mais ansioso que aflito, pois desejava saber o meu papel naquele set de filmagem.

Depois de andar de um lado para o outro à procura do pessoal, um rapaz me informou que eles estavam filmando em uma fazenda a aproximadamente dez quilómetros de São Roque.

- O senhor pode seguir a estrada que a fazenda fica do lado direito, disse ele tentando me ajudar.

Achei que andar dez quilômetros era muito para a minha cabeça e principalmente para os meus pés. Resolvi ficar na pensão, puxar uma cadeirinha, pedir um Drury's e tentar agüentar São Roque até a hora do almoço.

Quando a equipe chegou da filmagem percebi uma invasâo. Todos se sentaram e iam fazendo pratos verdadeiramente monstruosos, sem sequer perguntar ao companheiro do lado se ele gostaria de um pouco de feijão. Acho que nesse momento esqueci-me de qualquer ideal socialista e pensei: "O que ê que eu estou fazendo aqui no meio desses 
bichos? Será que meus anos na universidade servem para assistir a cenas desse tipo e depois sair por esse Brasil defendendo o cinema nacional?"

Procurei o sr. William, aquele que pensei ser o diretor do filme, para tentar saber que função eu teria ali. Conversa vai, conversa vem, racionalizações sobre os problemas de produção do cinema brasileiro, a necessidade de se produzir, etc... levaram-me a ter certeza de que eu estava lá como guardião do equipamento da ECA. Por um lado eu faria isso, mas também não ficaria ali sentado na porta de um bar sem fazer nada. Então comuniquei ao sr. William que iria embora e levaria comigo o equipamento pertencente à escola.

Catástrofe. Furacão em São Roque. Terremoto.

- Não, disse-me William. Não faça isso senão o filme não vai sair, e af eu estarei ferrado.

Logo depois, numa reunião particular entre eu, William e Regatieri, descubro que o filme era do Regatieri em todos os sentidos: produção (dinheiro), direção e qualquer outra decisão que fosse tomada. E para que eu ficasse lá, fui promovido a cenografo e figurinista. Preocupado com o certificado de qualidade do INC, William me propôs que déssemos uma "melhorada" no visual do espetáculo.

$\mathrm{E}$ af começaram os meus problemas. $\mathrm{O}$
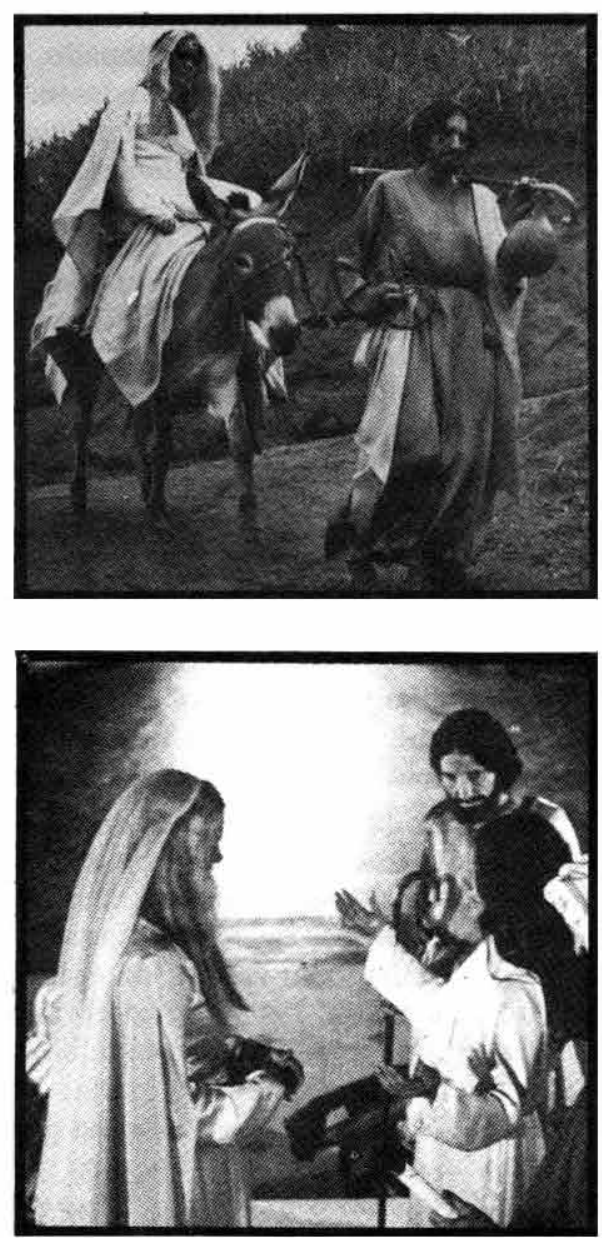
primeiro, é claro, dizia respeito às fofocas sobre aquele menino vindo de São Paulo para mexer em tecidos e fabricar algumas roupas. Os "romanos", durante algum tempo, recusaram-se a tirar as medidas para que se pudessem confeccionar os trajes. Foi necessário o comando forte de Regatieri para que eles obedecessem. "Quanta ditadura, pensava eu; a de Brasflia, a de São Roque e tantas outras espalhadas pelo Brasil".

Depois que os "romanos" se convenceram de que não havia outra solução a não ser usarem os saiotes, a vestimenta deles tornou-se ainda mais complexa. Inventei, um dia antes, armaduras de metal, pintadas de marrom e presas com arames. Fora a colocação dos mantos e das braçadeiras. Foram gastas muitas horas para aprontar os romanos para as cenas.

Meu segundo problema grave foi justamente com o romano titular do espetáculo do Regatieri. Esse romano aparecia no começo da encenação com Herodes e, no fim da peça, no momento da crucificação. Quase saiu uma briga na praça, pois o titular não desejava renunciar aos dois momentos, mesmo com o William explicando que no cinema as coisas não podiam ser assim. Mas foi o Regatieri que, sem maiores explicações, escalou o romano titular para a cena final.

Passada uma semana, chegaram os primeiros copiões, e lá fomos todos nós para Colatina. Lembro-me que vários caminhões safram de São Roque para a projeção.

Lá chegando, houve aquela confusão que sempre antecede exibiçōes de copiōes. William explicava que era apenas um copião, o que para aquele povo não fazia a mínima diferença. Mas no fundo ele estava preocupado com a ausência de som, sem lembrar que a vida de Cristo exibida lá ainda era aquela versão muda.

Lá pelas tantas entrou a primeira cena do Cristo, e em toda a minha vida juro nunca ter presenciado cena igual. Não a da tela, mas a da platéia que saiu de suas poltronas e se ajoelhou nos dois corredores do cinema. Para eles não era uma representação na tela, e nem tampouco uma seqüência do filme, pois haviam assistido às filmagens. Era o Cristo.
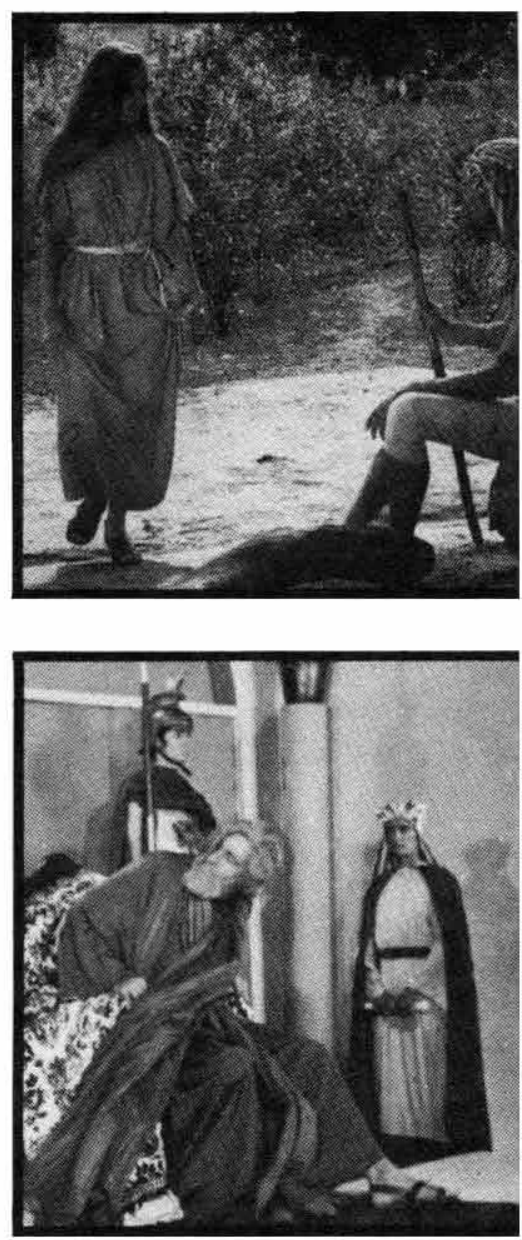

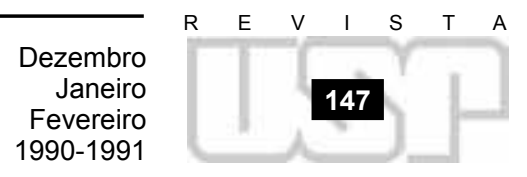


Nem eu nem o William estávamos entendendo mais nada, e depois dessa manifestação diante de um copião desordenado, percebemos que era melhor deixar o Regatieri dirigir o filme como ele bem entendesse.

O roteiro tinha sido escrito e preparado, porém o ZE, como carinhosamente o chamávamos, preferia seguir o testamento. As cenas deviam reproduzir com "fidelidade" o Evangelho.

Um dos casos mais engraçados aconteceu na filmagem do presépio. A primeira dificuldade foi a de se encontrar em São Roque um bebê que pudesse fazer a cena. $O$ único infeliz tinha quase um ano, e William safa explicando que isso fazia parte do milagre.

Tudo pronto, luz colocada, as fogueiras dos pastores ao fundo, a equipe segurando os animais, Maria e José diante da manjedoura, quando entra em disparada uma figura e arranca a Maria do presépio a tapas. Era o seu noivo que descobrira que ela andava transando com o assistente de direção. Eu, que estava segurando as cabras, cal na gargalhada pelo insólito de ver a Virgem Maria arrancada do presépio, e deixei que os animais se fossem. Afinal de contas não é sempre que se vê a Virgem Maria disputada por vários homens...

Naquela localidade, presenciei um outro espetáculo fantástico: a feira que desce do nordeste até regiōes do Espírito Santo. É uma interessante feira de barganhas, onde o povo da região permuta os objetos mais inusitados. A feira havia começado, mas o povo de São Roque ainda estava filmando no colégio agrícola perto de Santa Teresa, e era uma seqüência de multidão, o que significava quase toda a cidade.

Nesse dia, já muito aborrecido com a marginalização imposta pelo resto da equipe, resolvi sentar-me diante da igreja e observar a preparação da feira.

As horas passaram, e eu me mantive distrafdo. Mas, de repente, comecei a notar coisas verdadeiramente estranhas: fariseus, rabinos e romanos se misturavam entre pessoas também vestidas com roupas da época, trocando objetos, tomando cerveja no bar, discutindo futebol, de mãos dadas em namoros. Porém, o máximo, a consagração, se deu quando reparei em Cristo permutando um objeto de ouro por um radinho de pilha.

Levantei-me da escada da igreja, na qual estava tentando desenhar um cenário, pois quase tudo acabava se passando na porta da igreja. Fui até o bar, pedi uma dose dupla de Drury's, que entornei em alguns goles, desafiei o romano no bilhar e ganhei a partida: havia vencido o império romano no qual Cristo estava mais preocupado com as curvas da estrada de Santos, naquela época o sucesso de outro rei, que não o de Israel, em outro tempo. A estadia em São Roque chegou ao fim, e estávamos esperando apenas o último dia de filmagem: a crucificação. Regatieri havia sido tão realista em suas leituras do Evangelho e outras pesquisas talvez, que mandou confeccionar uma cruz com o mesmo peso da cruz usada por Cristo. $\mathrm{E}$ como se isso não bastasse para o ator, a via crucis era bastante longa.

O ânimo pela crucificação era tão grande que toda a cidade participou das filmagens, inclusive ajudando a equipe com o material necessário para os planos mais próximos. $\mathrm{E}$ isso durou horas, sem que vivalma percebesse que o ator representando Cristo estava quase morrendo! E ele saiu da cruz para o hospital em Colatina, tendo ficado o realismo pela metade.

Depois disso ainda faltavam algumas cenas suplementares, que acabaram sendo cortadas na montagem; mas eu estava resolvido a pegar o meu equipamento e voltar a São Paulo. E para falar a verdade, a sensação que eu estava tendo era a de que não iriam me chamar para a montagem.

Pé na estrada, e ainda com tempo para ir pela costa, mas sem poder aproveitar uma praia.

\section{A MONTAGEM}

De repente, William e Regatieri despencam em São Paulo, com os copiões, e logo avisei o Rudá de Andrade que montaria o filme na escola como havfamos combinado.

Nessa época meus colegas gênios usavam as melhores moviolas, que são as de oito pratos e seis pratos. Para mim sobrou a de quatro pratos. E essa lição foi fundamental: colegas em moviolas "mais sofisticadas" eram incapazes de produzir filmes razoáveis, pois se idéia e prática não fizerem parte de uma harmonia, é impossf́vel pensar em montagem. Nunca liguei, e até hoje não ligo, para o número de pratos, contanto que eu possa fazer as operações básicas de sincronismo. $\mathrm{O}$ resto, uma boa memorização acaba resolvendo. 
Bem, a primeira coisa que fiz antes de entrar na moviola foi assistir ao copião projetado, etapa básica inclusive para a escolha de planos e verificação de eventuais defeitos. Até hoje condeno quando alguém, no afă de ver o material, resolve passá-lo em moviola.

Fiz questão de marcar posição em relação às moviolas, pois já naquela época o meu sentimento sobre montagem transcendia às especificaçōes técnicas, ou melhor dizendo, aos detalhes que as engenharias colocam com o objetivo de serem funcionais. E várias vezes me perguntei: "Engenheiros são montadores?"

Meio como primo pobre, com um material "desprezfvel" trazido por um sujeito do Espírito Santo com mais um outro, chamado William Cobbett, que foi o maior distribuidor de filmes russos exibidos entre nós, achei que a moviola de quatro pratos era perfeita, e tinha quase certeza de que Cristo não iria se importar.

Armar um copiâo é tarefa simples: com a numeração fornecida pela claquete, colocamos em ordem os planos, as coberturas correspondentes a esses planos, dividimos as cenas e as seqüências. No entanto, no caso do Regatieri foi mais complicado do que havia pensado. Ele não queria cortar um fotograma, nem os da claquete. Lembrei-me muito dos meus dezoito anos de mãos e nucas.

Acho que seria um milagre demovê-lo da idéia de nada cortar, mesmo que William, do seu lado, fizesse os maiores discursos sobre Eisenstein e os montadores russos; mas isso não adiantava nada, pois nem Eisenstein nem os russos estavam no Evangelho.

Foi ar que percebemos ter Regatieri uma alimentação bastante regular, levando seu farnel para a moviola: maçãs, pêras, ameixas. Terminado um perfodo de montagem, resolvemos dar uma esticada a um restaurante da av. Santo Amaro, na época um dos poucos que rodava a noite inteira. Imaginem só o tipo de comida para um final de madrugada! Lembro-me até hoje que eu fiquei na sopa (leve) e que Regatieri pediu lombo de porco. E á aconteceu o previsto, pois Regatieri teve um desarranjo intestinal, e lá nos mandamos, eu e o William, para a moviola.

Nesse dia nos divertimos muito, e a tesoura funcionou com uma tremenda rapidez. A seqüência do presépio, escolhida para iniciar a montagem, aconteceu em menos de um período.

Acho que não havia trabalhado tanto em minha vida como naquele dia. Cheguei em casa exausto, mas antes verifiquei se o Regatieri estava bem. Deitei-me, e várias idéias começaram a passar pela minha cabeça: "Que absurdo fazer uma estréia em longa-metragem com um filme sobre a vida de Cristo, ainda mais com um diretor que não entendia nada de cinema e, alêm do mais, dirigiu o filme com um Evangelho na mão. Será que aquilo daria certo, será que eu chegaria ao fim com um filme montado?" Como os meus colegas gênios, eu tambêm me considerava um gênio, porem aberto o suficiente para aceitar tal proposta. De onde Regatieri havia tirado aquela estrutura de auto popular para as suas apresentações em São Roque? Não podia me esquecer que ele era um ex-seminarista. A sua noção de "realismo" aproximava-se muitas vezes do circo-teatro, já que algumas figuras eram extremamente estereotipadas, como o caso de Judas, do Demônio (copiado de alguma reprodução sem entender um sentido mais profundo) e de outras que passavam pelas imagens.

Mesmo negando valores artísticos ao que montava, contraditoriamente achava-me fazendo um trabalho de capital importância, já que ele seria a realização máxima de muitos cineastas que tentam chegar ao popular e não conseguem. O presépio, por exemplo, continha em sua concepção o recolhimento que o artista plástico pre-renascentista fazia de seus tipos, e que no fundo eram síntese de vários rostos que habitaram este mundo. Da mesma forma, aquela gente humilde de São Roque estava deixando marcas em pelfcula, e eu tinha a estranha sensação de estar articulando imagens de uma representação passada há vinte séculos e conhecer todas aquelas caras, inclusive o deslize da Virgem Maria com todos os seus namorados, ajoelhada ao lado de José.

Quando Regatieri viu a cena do presepio montada, exclamou:

- É isso mesmo, é isso mesmo que eu quero.

E daf em diante o trabalho transcorreu com tranqüilidade, apenas faltava achar uma linha condutora para o trabalho da montagem. Como havia sido filmado em quadros, ficava muito complicado estabelecer as passagens de tempo interseqüênciais para que o drama se contasse. A cada passada do copião na moviola, eu tentava quebrar a cabeça, sem perceber que me encaminhava por uma vertente completamente errada. Estava tudo ali, o teatro do Regatieri na integra, essencialmente preservado, a não ser pelos efeitos de cenário e "roupas" que havfamos confeccionado para atingir um melhor critério de

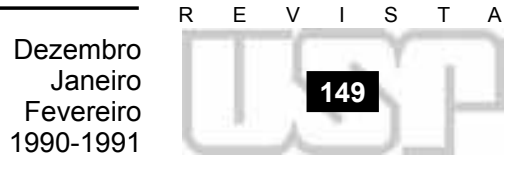


qualidade. No fundo, o fio condutor da montagem era muito parecido com aquele que damos aos documentários, quando os temas propostos e escolhidos fluem independentes do trabalho de uma montagem num filme ficcional.

Não cabia a mim discutir se o filme era bom ou ruim. Cabia a mim executar um trabalho que "violentasse", através do corte, a concepção primitiva que Regatieri tinha desse drama brblico.

Um dos fatos interessantes em São Roque ê que, ao rodar uma cena, Regatieri se referia ao ator pelo seu nome brblico e não pelo seu nome de batismo. Além do mais, para ele, a trilha sonora eram as músicas natalinas, sendo Noite feliz a do presépio.

Af eu me perguntava: “Que tipo de discussão cinematográfica devo fazer?" Ou mesmo: "Vale a pena fazer algum tipo de discussão cinematografica imediata, se o caráter deste filme parece-me muito mais mediato e ligado à memória do cinema brasileiro?".

Logo percebi que a minha estréia num filme de ficção de longa-metragem era uma grande estréia no documentário de longa-metragem, pois jamais poderia, e nem posso hoje, considerar $A$ vida de Cristo como um filme que possa ser inscrito no ficcional.

Mesmo assim, por ser um filme destinado ao lançamento comercial, fui obrigado a usar da montagem e do corte para embutir um drama que tivesse pelo menos uma seqüencialidade em sua construção, valendo-me da montagem paralela, da repetição de planos, da inserção de algumas coberturas e, o que me parece mais magistral, da tentativa de interpretar as palavras da cruz aproveitando, na forma de flashes, algumas imagens que haviam sido importantes na vida de Jesus. Não se tratava de um flashback, pois este não se caracterizava pelo retrocesso cênico. A ação da cruz continuava, e nessa cruz havia um homem permitindo que aquele discurso fosse atualizado. Não me parecia, esteticamente, coisa para se admirar, mas a agonia de Cristo ficou mais forte e mais densa dentro da narrativa do Regatieri.

Sem querer, eu estava tangenciando a problemática da metáfora, ao substituir o plano da cruz por imagens que não teriam lugar na articulação, não fosse a idéia de associar diversos momentos com a crucificação; e, ao mesmo tempo, deixava à metonímia a organização geral do tempo do filme. Nesse sentido, e tentando "experimentar" no drama do Regatieri, aproximava-me de pontos capitais da montagem cinematográfica, tais como ter por referência um material que iria para o lixo e dar a ele um poder de associação que só foi de fato descoberto quando os planos foram unidos. $E$ isso não escapava da linha condutora encontrada para o filme, pois foi exatamente na estrutura de quadros, nos quais muitas vezes cabiam os elementos mais díspares, que acabei percebendo possibilidades que iam alem do "registro documental" feito por Regatieri.

Se, ao invés de filmar o seu teatro de Semana Santa, Regatieri resolvesse contratar artistas e técnicos gabaritados em diversas especialidades no campo das expressões, talvez tivéssemos como resultado cenários suntuosos, figurinos de primeira qualidade, atores profissionais atuando no set de filmagem, produtores, assistentes e aquela parafernália. Mas e dar? Onde ficaria o seu pequeno drama de Semana Santa que se transformou em filme de longa-metragem lançado comercialmente? No fundo, que importância adquirem para as expressões artísticas as classificações como documentário, ficção, semidocumentário? Não importa de qual forma o filme seja classificado, como se isso fosse a principal discussão sobre ele. Importa sim saber que existe no Brasil, Espírito Santo, uma localidade chamada São Roque onde tudo aconteceu.

No último dia de montagem, embalamos todo o material e caminhamos da ECA ao Rei das Batidas. Como sempre sou atento a detalhes formais, havia trancado a moviola de quatro pratos e entregue a chave para o meu colega que montava na de oito pratos, até então proibida para mim. Eu fui, e o meu colega ficou. Parece ser essa a contingência maior de minha vida, quando me deparo com portas.

Regatieri e William foram para casa, e eu escolho amanhecer na av. Santo Amaro; sonolento, depois de alguns tragos senti que os raios de sol batiam no meu rosto. Pensei em São Roque e naquelas manhãs sentado na escadaria da igreja.

A roda-gigante do parque de diversões, lá para baixo do Cine Graúna, estava com suas luzes apagadas. Essa imagem fixou-se nos meus olhos de criança quando, nesses lugares de emoções, ficava eletrizado com o algodão doce de mentira, saindo de uma estranha máquina, para se derreter em minha boca. 